\title{
Pengaruh Promosi Jabatan Terhadap Kinerja Karyawan pada PT. Beringin Life di Jakarta
}

\author{
Rofiq Noorman Haryadi ${ }^{1}$, aDenok Sunarsi ${ }^{2}$, Heri Erlangga ${ }^{3}$, Nurjaya ${ }^{4}$, Ana \\ Wijandari ${ }^{5}$ \\ ${ }^{1,5}$ STEBIS Bina Mandiri, Cileungsi Kidul, Kec. Cileungsi, Bogor, Jawa Barat \\ ${ }^{2}$ Universitas Pamulang, Tangerang Selatan, Banten, Indonesia \\ ${ }^{3}$ Universitas Pasundan, Bandung, Jawa Barat, Indonesia \\ ${ }^{4}$ Universitas Suryakancana, Cianjur, Jawa Barat, Indonesia \\ aProgram Doktor Ilmu Manajemen, Program Pascasarjana, Universitas Pasundan, \\ Bandung, Jawa Barat, Indonesia \\ Email: 'rofiq.stebis@gmail.com
}

\begin{abstract}
This study aims to determine the effect of promotion on employee performance at PT. Beringin Life in Jakarta. The method used is explanatory research with a sample of 60 respondents. The analysis technique uses statistical analysis with regression, correlation, determination and hypothesis testing. The results of this research variable of job promotion obtained an average score of 3,368 with good criteria. Employee performance variable obtained an average score of 3.833 with good criteria. Promotion has a positive and significant effect on employee performance with the regression equation $Y=9.840$ $+0.846 \mathrm{X}$, and the correlation coefficient is 0.705 or has a strong relationship with a determination value of $49.8 \%$. Hypothesis testing obtained a significance of $0.000<0.05$.
\end{abstract}

Keywords: Promotion, Employee Performance.

\begin{abstract}
Abstrak
Penelitian ini bertujuan untuk mengetahui pengaruh promosi jabatan terhadap kinerja karyawan pada PT. Beringin Life di Jakarta. Metode yang digunakan adalah explanatory research dengan sampel sebanyak 60 responden. Teknik analisis menggunakan analisis statistik dengan pengujian regresi, korelasi, determinasi dan uji hipotesis. Hasil penelitian ini variabel promosi jabatan diperoleh nilai rata-rata skor sebesar 3,368 dengan kriteria baik. Variabel kinerja karyawan diperoleh nilai rata-rata skor sebesar 3,833 dengan kriteria baik. Promosi jabatan berpengaruh positif dan signifikan terhadap kinerja karyawan dengan nilai persamaan regresi $\mathrm{Y}=9,840+0,846 \mathrm{X}$, dan nilai koefisien korelasi 0,705 atau memiliki tingkat hubungan yang kuat dengan nilai determinasi $49,8 \%$. Uji hipotesis diperoleh signifikansi $0,000<0,05$.
\end{abstract}

Kata Kunci: Promosi Jabatan, Kinerja Karyawan.

\section{PENDAHULUAN}

Sumber daya manusia membuat sumber daya organisasi lainnya berjalan. Mengingat begitu vitalnya peranan sumber daya manusia dalam suatu perusahaan, sudah sepatutnya jika suatu perusahaan memperhatikan aspek-aspek kerja yang berkaitan dengan sumber daya manusia. Hal tersebut diharapkan karyawan yang memiliki motivasi 
kerja yang kuat merupakan keunggulan kompetitif suatu perusahaan. Pada dasarnya, perusahaan bukan saja mengharapkan karyawan yang memiliki tingkat intelejensi tinggi, tetapi yang terpenting mereka mau bekerja giat dan berkeinginan untuk mencapai hasil kerja yang optimal. Kemampuan, kecakapan, dan keterampilan karyawan tidak ada artinya bagi perusahaan tanpa adanya kerja keras.

Pengembangan sumber daya manusia merupakan cara agar dapat mempertahankan eksitensi kerja semua komponen organisasi. Sebuah organisasi harus mampu mengoptimalkan kemampuan sumber daya manusia yang dimilikinya agar pencapaian sasaran dapat terlaksana, namun hal tersebut tidaklah sederhana perlu pemahaman yang baik tentang organisasi terpakai sesuai kebutuhan, tentunya pimpinan perusahaan perlu pemahaman yang baik tentang organisasi, perlu ada strategi pengembangan yang matang agar sumber daya manusia yang dimiliki sebuah organisasi terpakai sesuai kebutuhan, tentunya pimpinan perusahaan perlu memotivasi karyawannya yaitu dengan promosi jabatan.

Masalah yang timbul adalah bahwa kebutuhan masing-masing orang berbeda satu dengan yang lain. Maka perusahaan haruslah menjadi suatu lembaga yang menyediakan kesempatan dalam pemenuhan kebutuhan bagi para pekerjanya. Seseorang cenderung bekerja dengan penuh semangat apabila promosi jabatan dapat diperolehnya dari pekerjaannya dan promosi jabatan kerja karyawan merupakan kunci pendorong moral, dan kinerja karyawan karyawan dalam mendukung terwujudnya tujuan perusahaan (Hasibuan, 2011:203). Menurut Siagian (2012:169) promosi jabatan adalah pemindahan karyawan dari satu jabatan atau tempat kepada jabatan atau tempat lain yang lebih tinggi disertai tugas, tanggung jawab dan wewenang yang lebih tinggi dari jabatan yang diduduki sebelumnya.

Promosi jabatan dilaksanakan untuk mengoptimalkan sumber daya manusia yang dimiliki organisasi, selain itu promosi jabatan bertujuan untuk meregenerasi sumber daya manusia dalam organisasi demi kelangsungan organisasi. Kinerja karyawan karyawan merupakan tolak ukur utama dalam pengembangan sumber daya manusia. Menurut Hasibuan (2016:105) kinerja karyawan adalah suatu hasil kerja yang dicapai seseorang dalam pelaksanaan tugas - tugas yang dibebankan kepadanya yang didasarkan pada kecakapan dan ketepatan waktu. Menurut Mangkunegara (2016:67) kinerja karyawan adalah hasil kerja secara kualitas dan kuantitas yang dicapai oleh seseorang karyawan dalam melaksanakan tugasnya sesuai dengan tanggung jawab yang diberikan kepadanya.

Beringin Life merupakan bagian atau divisi dari perusahaan asuransi jiwa di Indonesia yang turut berkiprak di industri jasa dalam hal asuransi baik asuransi jwa, asuransi barang maupun pendidikan.

Masalah sumber daya manusia yang menyangkut kinerja karyawan juga terjadi di Beringin Life. Dalam hal ini Beringin Life membagi karyawan atas pegawai dinas dalam dan pegawai dinas luar (agen). Para pegawai sangat membutuhkan kinerja karyawan yang tinggi, karena dengan memiliki kinerja karyawan yang tinggi, tujuan yang realitas, rencana kerja yang menyeluruh akan berjalan sesuai dengan yang diharapkan. Hal tersebut akan berdampak pada target premi yang ditentukan perusahaan dapat tercapai. Untuk mencapai target premi, ada dua kiat utama yang dijalankan.

Pertama mengedapankan kepentingan dinas di atas kepentingan pribadi. Kedua, mengadakan pertemuan rutin untuk memberikan motivasi, evaluasi dan menambah skill penjualan yang baik terutama untuk mengahadapi prospek (calon nasabah/pemegang polis) serta mensosialisasikan nota-nota dinas yang berhubungan dengan produk asuransi ataupun teknis pelaksanaannya.

Dalam hal ini peran agen Beringin Life sangat vital. Pada umumnya para agen asuransi jiwa belum memiliki kualifikasi seperti yang diharapkan, ditandai dengan 
tingginya agen yang keluar. Dengan adanya masalah tersebut, tujuan pemberdayaan agen guna meningkatkan pendapatan premi dan pertumbuhan industri asuransi jiwa, bisa saja tidak tercapai secara optimal. Hal tersebut berkaitan dengan promosi jabatan dan kinerja karyawan. Artinya, agen yang tidak termotivasi biasanya memiliki kinerja karyawan yang kurang bagus dan kurang menikmati pekerjaan sehingga memutuskan berhenti atau malah diberhentikan. Hal tersebut menandakan adanya kinerja karyawan agen Beringin Life antara kondisi kerja dengan yang diharapkan. Hal lain yang menyebabkan kinerja karyawan yang belum tercapai adalah rendahnya intensitas dalam melakukan pertemuan rutin untuk memberikan motivasi, evaluasi dan menambah skill penjualan yang baik. Masalah promosi jabatan terhadap kinerja karyawan memiliki peranan penting dalam rangka memenuhi kebutuhan kepentingan perusahaan akan karyawannya untuk benarbenar mampu dan menguasai jenis-jenis pekerjaan baru tersebut.

Kinerja sangat penting bagi organisasi karena mengingat kinerja yang tinggi tentu dapat mengurangi angka absensi atau tidak bekerja karena malas, disamping itu juga dengan kinerja yang tinggi dari buruh dan karyawan maka pekerjaan yang diberikan atau ditugaskan kepadanya akan dapat diselesaikan dengan waktu yang lebih singkat atau lebih

Berdasarkan pemaparan di atas, maka penulis membuat judul penelitian :Pengaruh Promosi Jabatan Terhadap Kinerja Karyawan Pada PT. Beringin Life Di Jakarta”.

\section{RUMUSAN MASALAH}

a. Bagaimana promosi jabatan pada PT. Beringin Life di Jakarta ?.

b. Bagaimana kinerja karyawan pada PT. Beringin Life di Jakarta ?.

c. Adakah pengaruh antara promosi jabatan terhadap kinerja karyawan pada PT. Beringin Life di Jakarta?.

\section{TINJAUAN PUSTAKA}

\section{A. Promosi Jabatan}

Promosi jabatan merupakan salah satu dari beberapa macam pengembangan karier, mendapatkan promosi jabatan merupakan sebuah impian atau tujuan dari para pegawai karena apabila seorang pegawai mendapatkan promosi berarti dia mendapatkan balas jasa yang diberikan oleh instansi atau perusahaan atas kinerja yang telah dilakukannya. Pengertian promosi jabatan lainnya dikemukakan Hasibuan (2020:108) yaitu "Promosi berarti perpindahan dari suatu jabatan ke jabatan lain yang mempunyai status dan tanggung jawab yang lebih tinggi. Biasanya perpindahan yang lebih tinggi disertai dengan peningkatan gaji/upah lainnya, walaupun tidak selalu demikian"

B. Kinerja Karyawan

Menurut Mangkunegara (2019:75) pengertian kinerja adalah hasil kerja secara kualitas dan kuantitas yang dicapai oleh seorang pegawai dalam melaksanakan tugasnya sesuai dengan tanggung jawab yang diberikan kepadanya.

\section{METODE PENELITIAN}

A. Populasi

Yang dijadikan sebagai populasi dalam penelitian ini adalah responden yang berjumlah 60 responden PT. Beringin Life di Jakarta

B. Sampel

Teknik pengambilan sampling dalam penelitian ini adalah sampel jenuh, dimana semua anggota populasi dijadikan sebagai sampel. Dengan demikian sampel dalam penelitian ini sampel yang digunakan berjumlah 60 responden. 
C. Jenis Penelitian

Jenis penelitian yang dipakai adalah asosiatif, dimana tujuannya adalah untuk mengetahui atau mencari keterhubungan antara variabel independen terhadap variabel dependennya

D. Metode Analisis Data

Dalam menganalisis data digunakan uji validitas, uji reliabilitas, analisis regresi linier sederhana, analisis koefisien korelasi, analisis koefisien determinasi dan pengujian hipotesis.

\section{HASIL PENELITIAN}

A. Analisis Deskriptif

Pada pengujian ini digunakan untuk mengetahui skor minimum dan maksimum skor tertinggi, ratting score dan standar deviasi dari masing-masing variabel. Adapun hasilnya sebagai berikut:

Tabel 1. Hasil Analisis Descriptive Statistics

\section{Descriptive Statistics}

\begin{tabular}{lr|r|r|r|r} 
& N & Minimum & Maximum & Mean & Std. Deviation \\
\hline Promosi jabatan (X) & 60 & 29 & 44 & 33.68 & 3.703 \\
\hline Kinerja Karyawan (Y) & 60 & 29 & 49 & 38.33 & 4.440 \\
\hline Valid N (listwise) & 60 & & & & \\
\hline
\end{tabular}

Promosi jabatan diperoleh varians minimum sebesar 29 dan varians maximum 44 dengan ratting score sebesar 3,368 dengan standar deviasi 3,703. Skor ini termasuk pada rentang sakala 3,40 - 4,19 dengan kriteria baik atau setuju. Kinerja karyawan diperoleh varians minimum sebesar 29 dan varians maximum 49 dengan ratting score sebesar 3,833 dengan standar deviasi 4,440. Skor ini termasuk pada rentang sakala 3,40 - 4,19 dengan kriteria baik atau setuju.

B. Analisis Kuantitatif.

Pada analisis ini dimaksudkan untuk mengetahui pengaruh variabel independen terhadap variabel dependen. Adapun hasil pengujian sebagai berikut:

\section{Analisis Regresi Linier Sederhana}

Uji regresi ini dimaksudkan untuk mengetahui perubahan variabel dependen jika variabel independen mengalami perubahan. Adapun hasil pengujiannya sebagai berikut:

Tabel 2. Hasil Pengujian Regresi Linier Sederhana

Coefficients $^{\mathrm{a}}$

\begin{tabular}{|c|c|c|c|c|c|}
\hline \multirow[b]{2}{*}{ Model } & \multicolumn{2}{|c|}{$\begin{array}{l}\text { Unstandardized } \\
\text { Coefficients }\end{array}$} & \multirow{2}{*}{$\begin{array}{c}\text { Standardized } \\
\text { Coefficients } \\
\text { Beta }\end{array}$} & \multirow[b]{2}{*}{$\mathrm{t}$} & \multirow[b]{2}{*}{ Sig. } \\
\hline & B & Std. Error & & & \\
\hline 1 (Constant) & 9.840 & 3.782 & & 2.602 & .012 \\
\hline Promosi jabatan (X) & .846 & .112 & .705 & 7.580 & .000 \\
\hline
\end{tabular}

a. Dependent Variable: Kinerja Karyawan (Y) 
Berdasarkan hasil pengujian pada tabel di atas, diperoleh persamaan regresi $\mathrm{Y}=9,840+0,846 \mathrm{X}$. Dari persamaan tersebut dijelaskan sebagai berikut:

1) Konstanta sebesar 9,840 diartikan jika promosi jabatan tidak ada, maka telah terdapat nilai kinerja karyawan sebesar 9,840 point.

2) Koefisien regresi promosi jabatan sebesar 0,846 , angka ini positif artinya setiap ada peningkatan promosi jabatan sebesar 0,846 point maka kinerja karyawan juga akan mengalami peningkatan sebesar 0,846 point

\section{Analisis Koefisien Korelasi}

Analisis koefisien korelasi dimaksudkan untuk mengetahui tingkat kekuatan hubungan dari variabel independen terhadap variabel dependen. Adapun hasil pengujian sebagai berikut:

Tabel 3. Hasil Pengujian Koefisien Korelasi Promosi jabatan Terhadap Kinerja

Karyawan.

Correlations $^{\mathrm{b}}$

Promosi jabatan

(X)

Kinerja Karyawan (Y)

\begin{tabular}{llr|r}
\hline Promosi jabatan $(\mathrm{X})$ & Pearson Correlation & 1 & $.705^{* *}$ \\
\cline { 2 - 4 } & Sig. (2-tailed) & & .000 \\
\hline Kinerja Karyawan $(\mathrm{Y})$ & Pearson Correlation & $.705^{* *}$ & 1 \\
\cline { 2 - 4 } & Sig. (2-tailed) & .000 & \\
\hline
\end{tabular}

**. Correlation is significant at the 0.01 level (2-tailed).

b. Listwise $\mathrm{N}=60$

Berdasarkan hasil pengujian diperoleh nilai korelasi sebesar 0,705 artinya promosi jabatan memiliki hubungan yang kuat terhadap kinerja karyawan.

\section{a. Analisis Koefisien Determinasi}

Analisis koefisien determinasi dimaksudkan untuk mengetahui besarnya persentase pengaruh dari variabel independen terhadap variabel dependen. Adapun hasil pengujian sebagai berikut:

Tabel 4. Hasil Pengujian Koefisien Determinasi Promosi jabatan Terhadap

Kinerja Karyawan.

\section{Model Summary}

\begin{tabular}{lr|r|r|r} 
Model & R & R Square & $\begin{array}{c}\text { Adjusted R } \\
\text { Square }\end{array}$ & $\begin{array}{c}\text { Std. Error of the } \\
\text { Estimate }\end{array}$ \\
\hline 1 & $.705^{\mathrm{a}}$ & .498 & .489 & 3.174 \\
\hline
\end{tabular}

a. Predictors: (Constant), Promosi jabatan (X)

Berdasarkan hasil pengujian diperoleh nilai determinasi sebesar 0,498 artinya promosi jabatan memiliki kontribusi pengaruh sebesar $49,8 \%$ terhadap 
kinerja karyawan, sedangkan sisanya sebesar 50,2\% dipengaruhi oleh faktor lain yang tidak dilakukan penelitian.

\section{b. Uji Hipotesis}

Pengujian hipotesis dengan uji t digunakan untuk mengetahui hipotesis mana yang diterima. Rumusan hipotesis: Terdapat pengaruh yang signifikan promosi jabatan terhadap kinerja karyawan.

Tabel 5. Hasil Uji Hipotesis Promosi jabatan Terhadap Kinerja Karyawan.

\section{Coefficients $^{\mathrm{a}}$}

\begin{tabular}{lr|r|r|r|r} 
& \multicolumn{2}{c|}{$\begin{array}{c}\text { Unstandardized } \\
\text { Coefficients }\end{array}$} & $\begin{array}{l}\text { Standardized } \\
\text { Coefficients }\end{array}$ & & \\
Model & B & Std. Error & Beta & $\mathrm{t}$ & Sig. \\
\hline 1 (Constant) & 9.840 & 3.782 & & 2.602 & .012 \\
\hline $\begin{array}{l}\text { Promosi jabatan } \\
(\mathrm{X})\end{array}$ & .846 & .112 & .705 & 7.580 & .000 \\
\hline
\end{tabular}

a. Dependent Variable: Kinerja Karyawan (Y)

Berdasarkan hasil pengujian pada tabel di atas, diperoleh nilai t hitung $>\mathrm{t}$ tabel atau $(7,580>2,002)$, dengan demikian hipotesis yang diajukan bahwa terdapat pengaruh yang signifikan atara promosi jabatan terhadap kinerja karyawan diterima.

\section{PEMBAHASAN HASIL PENELITIAN}

\section{a. Kondisi Jawaban Responden Variabel Promosi jabatan}

Berdasarkan jawaban responden, variabel promosi jabatan diperoleh ratting score sebesar 3,368 berada di rentang skala 3,40 - 4,19 dengan kriteria baik atau setuju.

\section{b. Kondisi Jawaban Responden Variabel Kinerja Karyawan}

Berdasarkan jawaban responden, variabel kinerja karyawan diperoleh ratting score sebesar 3,833 berada di rentang skala 3,40 - 4,19 dengan kriteria baik atau setuju.

\section{c. Pengaruh Promosi jabatan Terhadap Kinerja Karyawan}

Promosi jabatan berpengaruh signifikan terhadap kinerja karyawan dengan persamaan regresi $\mathrm{Y}=9,840+0,846 \mathrm{X}$, nilai korelasi sebesar 0,705 atau memiliki hubungan yang kuat dengan kontribusi pengaruh sebesar 49,8\%. Pengujian hipotesis diperoleh nilai t hitung $>t$ tabel atau $(7,580>2,002)$. Dengan demikian hipotesis yang diajukan bahwa terdapat berpengaruh signifikan antara promosi jabatan terhadap kinerja karyawan diterima.

\section{KESIMPULAN DAN SARAN}

1) Kesimpulan

a. Variabel promosi jabatan diperoleh ratting score sebesar 3,368 berada di rentang skala 3,40-4,19 dengan kriteria baik atau setuju.

b. Variabel kinerja karyawan diperoleh ratting score sebesar 3,833 berada di rentang skala 3,40 - 4,19 dengan kriteria baik atau setuju. 
c. Promosi jabatan berpengaruh signifikan terhadap kinerja karyawan dengan persamaan regresi $\mathrm{Y}=9,840+0,846 \mathrm{X}$, nilai korelasi sebesar 0,705 atau kuat dan kontribusi pengaruh sebesar 49,8\% sedangkan sisanya sebesar 50,2\% dipengaruhi faktor lain. Uji hipotesis diperoleh nilai $t$ hitung $>t$ tabel atau $(7,580>2,002)$.

\section{2) Saran}

a. Perusahaan secara periodek rutin melakukan penilaian kerja sehingga diketahui karyawan yang memiliki prestasi sehingga dapat dipromosikan ke jenjang yang lebih tinggi lagi.

b. Perusahaan harus selalu memberikan semangat dan apresiasi yang layak untuk memastikan karyawan memiliki semangat kerja yang tinggi.

\section{DAFTAR PUSTAKA}

Abdullah. M (2014). Manajemen dan Evaluasi Kinerja Karyawan. Yogyakarta: Penerbit Aswaja Pressindo.

Algifari. (2015). Analisis Regresi untuk Bisnis dan Ekonomi. Yogyakarta: BPFE.

Arikunto, Suharsimi (2014). Prosedur Penelitian Suatu Pendekatan Praktek. Jakarta: Rineka Cipta.

Bangun, Wilson. (2012). Manajemen Sumber Daya Manusia. Jakarta: Erlangga

Bejo Siswanto (2013) Manajemen Tenaga Kerja Rancangan dalam Pendayagunaan dan Pengembangan Unsur Tenaga Kerja. Bandung: Sinar Baru.

Dessler, G. (2006.). Manajemen Sumber Daya Manusia. Jilid II. Jakarta: Indeks.

Edi Sutrisno (2016). Manajemen Sumber Daya Manusia. Jakarta: Prenadamedia Group. Edi Sutrisno (2016). Manajemen Sumber Daya Manusia. Jakarta: Prenadamedia Group. George Terry R \& Rue, Leslie W. Rue (2016). Dasar-Dasar Manajemen. Jakarta Bumi Aksara.

Gerry Dessler (2016). Human Resources Management. Prenticehall. London: International Inc.

Handoko (2016). Manajemen Personalia dan Sumberdaya Manusia. Yogyakarta: BPFE. Hasibuan, Malayu S.P. (2016). Manajemen Sumber Daya Manusia. Edisi Revisi. Jakarta: PT Bumi Aksara.

Imam Ghozali (2017). “Aplikasi Analisis Multivariate Dengan Program SPSS”. Edisi Kelima. Semarang: Badan Penerbit Undip.

Istijanto (2014) “Riset Sumber Daya Manusia”. Jakarta: PT. Gramedia Pustaka Luthans Fred (2014). Organizational Behavior. Ney York: McGraw-Hill. New York.

Mangkunegara, Prabu Anwar. (2016). Evaluasi Kinerja SDM. Cetakan ke tujuh, PT Refika Aditama: Bandung.

Robbins, P.S, \& Judge, A.T. (2003). Organizational Behavior. Jakarta: Salemba Empat.

Saggaf, M. S., et al. (2021). Principal Leadership Function on Teacher Performance for Secondary Schools. International Journal of Educational Administration, Management, and Leadership, 57-64.

Santoso, Singgih (2015). Menguasai Statistik Multivariat. Jakarta: PT Elex Media Komputindo. 
Sedarmayanti (2016) Manajemen Sumber Daya Manusia, Reformasi Birokrasi dan Manajemen Karyawan Negeri Sipil, Cetakan Kelima, Bandung: PT Refika Aditama.

Sudjana (2014). Metode Statistika. Bandung: Tarsido.

Sugiyono (2017). Metode Penelitian Administrasi dilengkapi dengan Metode $R \& D$. Bandung: Alfabeta.

Suwanto. Et al. (2021). Pengaruh Komunikasi Internal Dan Disiplin Kerja Terhadap Kinerja Karyawan Pada Bagian Produksi PT Adicipta Boga Intiprima Jakarta Pusat. Jurnal Tadbir Peradaban. 1(3). 222-229

Veithzal Rivai (2015) Manajemen Sumber Daya Manusia Untuk Perusahaan. Jakarta: Raja Grafindo Persada.

Wibowo (2015). Manajemen Kinerja. Jakarta: PT. Raja Grafindo Persada.

Wicaksono, W., et al. (2021). Pengaruh Pelatihan, Motivasi Dan Budaya Organisasi Terhadap Kinerja Karyawan Pada PT Bank Mandiri, Tbk Di Jakarta. JENIUS (Jurnal Ilmiah Manajemen Sumber Daya Manusia), 5(1), 220-237. 